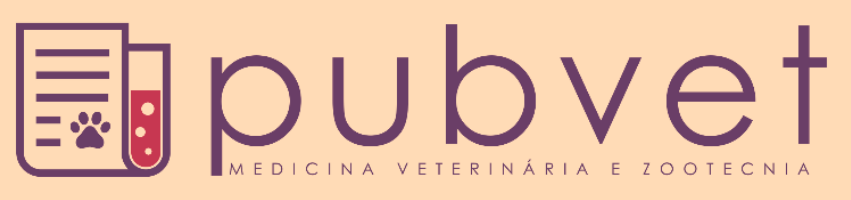

https://doi.org/10.31533/pubvet.v15n03a774.1-8

\title{
Eletroquimioterapia em mastocitoma canino: Relato de caso
}

\author{
Carolina Vianna Leite Otero ${ }^{1}$, Elisangela Guedes Duarte ${ }^{1}$, Paula Papareli de Oliveira ${ }^{1 *}$, Taine Elia \\ de Oliveira ${ }^{1}$, Bruno De Tullio Augusto Roque Lima ${ }^{2}$
}

${ }^{1}$ Discentes em medicina veterinária no Centro Universitário São Judas - Campus Unimonte. Santos - São Paulo, Brasil. ${ }^{2}$ Médico veterinário e Doutor no A.C. Camargo Cancer Center. São Paulo, Brasil.

*Autor para correspondência, E-mail: paulapapareli@hotmail.com

Resumo. Este relato de caso tem por objetivo descrever como a Eletroquimioterapia assim como outras ações conjuntas tais como neoadjuvância, ressecções cirúrgicas e a quimioterapia, atuaram no tratamento de um cão com 13 anos de idade diagnosticado com Mastocitoma de Grau III, alto grau de malignidade. A escolha da melhor terapia assim como o momento certo de cada processo foi baseado no exame de citologia aspirativa por agulha fina (CAAF) e confirmado pela especificação histológica tanto da lesão quanto dos linfonodos regionais. Conhecido como tumor de células redondas, o mastocitoma faz parte do grupo de neoplasias constituídas de mastócitos, de origem cutânea ou visceral. São mais comuns em cães, representando de $7 \%$ a $21 \%$ dos tumores de pele, destes de $11 \%$ a $21 \%$ possuem variações cutâneas malignas. Assim como neste relato, cerca de $45 \%$ dos casos ocorrem em membros pélvicos, região de períneo e genitália. Registros apontam para casos em cães com média de 8 anos de idade, mas já existem relatos em que o tumor atingiu caninos mais jovens, a partir dos 6 anos.

Palavras-chave: Câncer, cão, tumor cutâneo

\section{Electrochemotherapy in canine mast cell tumor: Case report}

Abstract. This case report aims to describe how Electrochemotherapy as well as other joint actions such as neoadjuvancy, surgical resections and chemotherapy, have acted in the treatment of a 13-year-old dog diagnosed with Grade III Mastocytoma, a high degree of malignancy. The choice of the best therapy as well as the right moment for each process was based on the examination of fine needle aspiration cytology (CAAF) and confirmed by the histological specification of both the lesion and the regional lymph nodes. Known as a round cell tumor, mastocytoma is part of the group of neoplasms consisting of mast cells, of cutaneous or visceral origin. They are more common in dogs, representing $7 \%$ to $21 \%$ of skin tumors, of these $11 \%$ to $21 \%$ have malignant skin variations. As in this report, about $45 \%$ of cases occur in the pelvic limbs, perineum region and genitalia. Records point to cases in dogs with an average age of 8 years, but there are already reports in which the tumor reached younger canines, from 6 years old.

Keywords: Cancer, dog, skin tumor

\section{Electroquimioterapia en mastocitoma: Reporte de caso}

Resumen. Este caso clínico tiene como objetivo describir cómo la Electroquimioterapia, así como otras acciones articulares como neoadyuvancia, resecciones quirúrgicas y quimioterapia, han actuado en el tratamiento de un perro de 13 años diagnosticado de Mastocitoma Grado III, un alto grado de malignidad. La elección de la mejor terapia y el momento adecuado para cada proceso se basó en el examen de citología por aspiración con aguja fina (CAAF) y confirmado mediante la especificación histológica tanto de la lesión 
como de los ganglios linfáticos regionales. El mastocitoma, conocido como tumor de células redondas, forma parte del grupo de neoplasias constituidas por mastocitos, de origen cutáneo o visceral. Son más comunes en perros, representando del $7 \%$ al $21 \%$ de los tumores de piel, de estos del $11 \%$ al $21 \%$ tienen variaciones cutáneas malignas. Como en este informe, aproximadamente el $45 \%$ de los casos ocurren en las extremidades pélvicas, la región del perineo y los genitales. Los registros apuntan a casos en perros con una edad promedio de 8 años, pero ya existen reportes en los que el tumor llegó a caninos más jóvenes, a partir de los 6 años.

Palabras clave: Cáncer, perro, tumor de piel

\section{Introdução}

A eletroquimioterapia (EQT) foi primeiramente descrita por Okino \& Mohri (1987). Os estudos fizeram uma associação de pulsos elétricos com quimioterápicos no tratamento de neoplasias, utilizando-se da combinação de duas técnicas: a quimioterapia em si e o uso de campos elétricos com o objetivo de potencializar a ação dos fármacos e induzir a regressão dos tumores (Rangel et al., 2008). Essa alternativa terapêutica quimioterápica pode ser realizada em conjunto, com administração de drogas citotóxicas, como cisplatina e a bleomicina, através de pulsos elétricos curtos que se propagam nas células e provocam a permeabilização intracelular, no qual é conhecido por eletro poração ou eletro permeabilização (Cemazar et al., 2008; Spugnini \& Baldi, 2014). Devem ser utilizados, segundo Daleck et al. (2016), pulsos retangulares, de 1000 a 1300 volts com duração de 100 microssegundos e a corrente máxima deve atingir 16 amperes. Para evitar destruição de pele e tecidos adjacentes, não é recomendado a utilização de campos elétricos muito elevados. Conforme ressalta Miller et al. (2013), a EQT é indicada principalmente para lesões pequenas e tumores superficiais, sendo que a terapia é externa em locais acessíveis no corpo do animal.

No Brasil a EQT é descrita no uso em tratamentos de cães e gatos com carcinoma mamário, mastocitoma, hemangioma, hemangiossarcoma, carcinoma de células escamosas, carcinoma basocelular, adenoma e adenocarcinoma perianais, linfossarcoma, fibrossarcoma, ganglioneuroblastoma, melanoma, melanocitoma, lipossarcoma, plasmocitoma, rabdomiossarcoma, neurofribrossarcoma, plasmocitoma, hemangiopericitoma, epulis acantomatoso e tumor venéreo transmissível canino (Daleck et al., 2016).

Descrito pela primeira vez por Bashford e colaboradores em 1905, o mastocitoma é conhecido como tumor de células redondas, e integra o grupo de neoplasias constituídas de mastócitos (Misdorp, 2004). A pele é o órgão mais acometido pelo tumor, embora haja registros também em região visceral (Souza et al., 2018). Felinos, bovinos, equinos e suínos, podem apresentar este tipo de neoplasia, mas a frequência maior ainda é em cães (Jarrett \& Mackey, 1974). Indicativos apontam casos de mastocitoma canino primário de origem em derme e região subcutânea, o que representa de 7 a $21 \%$ dos tumores de pele na espécie (Dean, 1988).

O diagnóstico de mastocitoma se faz pela citologia aspirativa por agulha fina (CAAF) no qual os grânulos são de fácil visualização ao microscópio. Entretanto, nos tumores mais indiferenciados à visualização dos mastócitos se torna mais difícil (Lavalle et al., 2003). Mesmo após a confirmação do diagnóstico pela CAAF, faz-se necessária a especificação histológica tanto da lesão quanto dos linfonodos regionais (Morris \& Dobson, 2001). Diferentemente do exame citopatológico a histopatologia analisa a arquitetura tecidual verificando se houve perda da organização tecidual e sua relação com os tecidos adjacentes, possibilitando determinar se as células tumorais são invasivas ou não (Morris \& Dobson, 2001; Withrow et al., 2013). Um outro recurso que pode ser utilizado para o diagnóstico dessa neoplasia é a histoquímica através da impregnação pela prata pelo método de AgNOR onde se avalia a quantidade das regiões controladoras de nucléolo e o índice de proliferação celular pela detecção imuno-histoquímica de marcadores nucleares como c-KIT (CD117) e Ki67 (Sledge et al., 2016; Vascellari et al., 2013).

O estadiamento tumoral mais utilizado é o preconizado pela União Internacional para o Controle do Câncer (UICC), denominado Sistema TNM onde se baseia na extensão anatômica da doença, levando 
em conta as características do tumor primário $(\mathrm{T})$, linfonodos regionais $(\mathrm{N})$ e a presença ou ausência de metástases a distância (M) (INCA, 2020).

A eletroquimioterapia como foi citada por diversos autores pode ser escolhida para facilitar os cirurgiões durante o tratamento em pacientes oncológicos. Há estudos iniciais que utilizaram da EQT e eletrosporação associado ao uso de fármacos quimioterápicos como bleomicina como potencializador para testes com camundongos portadores de tumores transplantados subcutâneos (Mir et al., 1991). Seus estudos, mesmo que em doses baixas, mostraram que podem reduzir os tumores e até erradicá-los. Conforme a medicina veterinária e a oncologia avançavam a técnica foi sendo aprimorada e novas formas de intervenção com a EQT mais recentes foram sendo descobertas.

Os tratamentos mais empregados para mastocitoma, atualmente, são: cirurgia, quimioterapia, eletroquimioterapia, radioterapia e inibidores de tirosina quinase. Os protocolos de tratamento podem incluir a ressecção cirúrgica, radioterapia, quimioterapia, crio cirurgia ou até mesmo a associação entre essas modalidades. A escolha do tipo de tratamento a ser utilizado dependerá dos fatores prognósticos, tendo como principais pontos de apoio a classificação histológica e o estadiamento clínico do tumor (Souza et al., 2018), assim como a avaliação clínica do paciente. Caso a opção seja por intervenção cirúrgica, o procedimento precisa de um conhecimento prévio de toda a extensão acometida para que se obtenha margens limpas após a remoção cirúrgica (Navega, 2011), evitando assim recidiva ou metástase.

O exame histopatológico reafirma o que a citologia sugere. Atesta a proliferação de mastócitos neoplásicos se estendendo da epiderme até a derme profunda, observando, assim, ser uma neoplasia altamente invasiva a planos profundos com bordos dos fragmentos enviados não preservados, concluindo o mastocitoma grau III / mastocitoma de alto grau. O grau histológico do mastocitoma segue uma classificação em graus, no total de três, proposto por Patnaik et al. (1984). Hoje, este sistema é amplamente utilizado na classificação dos mastocitomas, por ser um sistema satisfatório e íntegro, em que avalia o estadiamento tumoral e consequentemente características importantes da célula, tais como o número de grânulos citoplasmáticos, grau de anisocariose, número de figuras mitóticas e de invasão tumoral em tecidos adjacentes. Após classificado, é determinado o prognóstico da neoplasia em questão, auxiliando e direcionando assim o melhor tratamento para aquele paciente.

O procedimento cirúrgico, geralmente, é o tratamento de eleição para os mastocitomas, sendo que a quimioterapia, para os de grau III, deve ser sempre utilizada pelo fato de ter um alto potencial metastático (Cunha et al., 2017).

O objetivo deste trabalho é relatar um paciente canino com mastocitoma cutâneo refratário a neoadjuvância, que foi submetido a ressecção cirúrgica e eletroquimioterapia.

\section{Relato de caso}

Foi atendido no hospital veterinário Marapet, situado na cidade de Santos, São Paulo, um cão da raça American Bully de 13 anos, castrado, pesando 39,5 kg com diagnóstico citológico prévio de mastocitoma. A lesão media cerca de três $\mathrm{cm}$ de diâmetro localizada em região de prega inguinal de membro pélvico direito, com marcada presença de infiltrado inflamatório e edemaciada (Figura 1). Optou-se por iniciar a neoadjuvância, uma vez que, as margens cirúrgicas livres estariam fora de alcance no primeiro momento. $\mathrm{O}$ protocolo terapêutico instituído e recomendado em vários estudos para abordagem inicial no tratamento do mastocitoma foi à base de Vimblastina e Prednisolona. Como o paciente não apresentou remissão significativa após duas sessões de vimblastina, foi encaminhado para a cirurgia.

O nódulo de aproximadamente sete $\mathrm{cm}$ de diâmetro (Figura 2) foi removido cirurgicamente e as bordas adjacentes ao tumor foram expostas a eletroquimioterapia com Bleomicina via intravenosa, e o defeito cirúrgico foi fechado após divulsão das bordas remanescentes $\mathrm{O}$ paciente recuperou-se bem e após 3 dias, a ferida cirúrgica ainda edemaciada começou a apresentar deiscência de pontos (Figura 3). Durante o período de pós-operatório, o paciente recebeu Toceranib na dose de 3,25 mg/kg a cada 48 horas. Após 40 dias, ainda com a ferida exposta e cicatrizando por segunda intenção, o paciente apresentou recidiva tumoral e foi novamente exposto a ressecção cirúrgica (Figuras $4, \underline{5}$ e $\underline{6}$ ). Passados sete dias de pós-operatório em internação, o paciente recebeu alta, embora, no dia do pós-operatório apresentou deiscência total da sutura. Após 30 dias, os curativos diários contribuíram para a cicatrização 
(Figura 7), mas o paciente teve alterações séricas em função renal e hepática, perda de performance, queda no status clínico e foi eutanasiado.

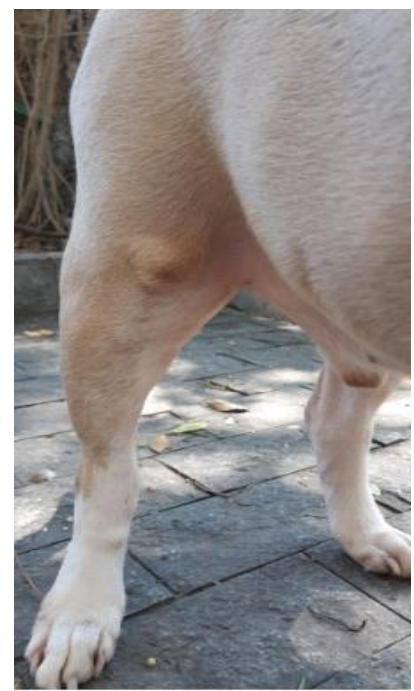

Figura 1. Tumor com $3 \mathrm{~cm}$ de diâmetro

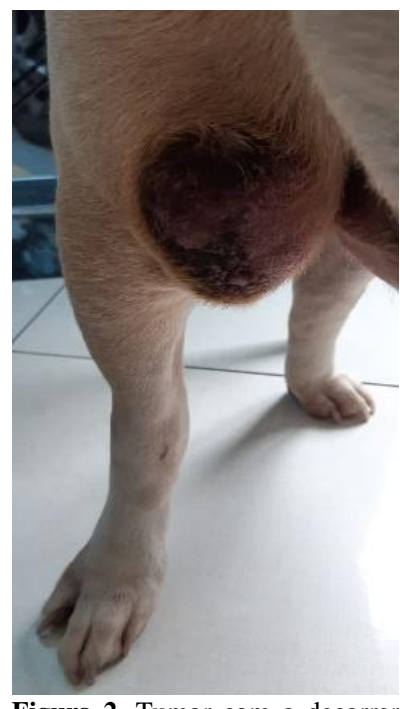

Figura 2. Tumor com o decorrer do tempo com $7 \mathrm{~cm}$.

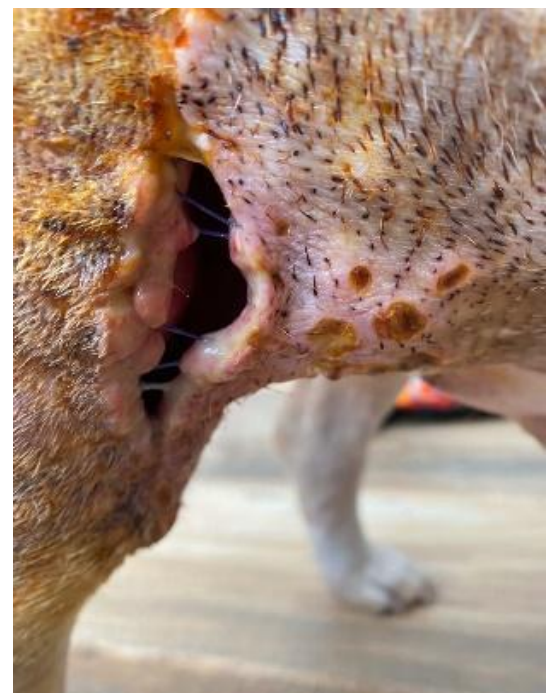

Figura 3. Resultado da primeira intervenção cirúrgica.

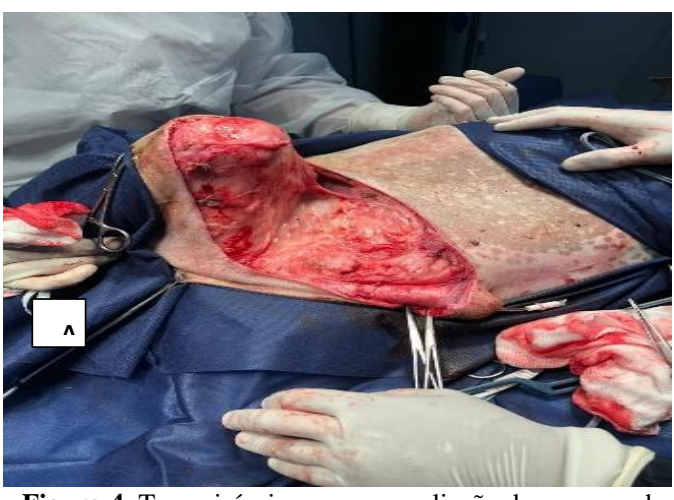

Figura 4. Transcirúrgico com a ampliação da margem de segurança

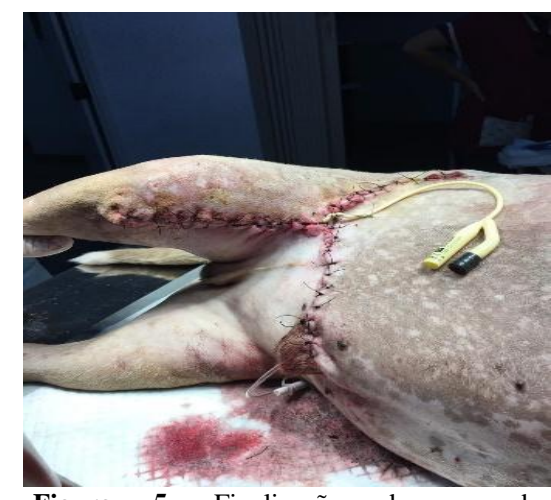

Figura procedimento cirúrgico

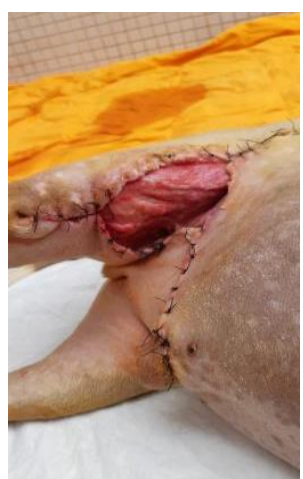

Figura 6. Dias posteriores a segunda cirurgia

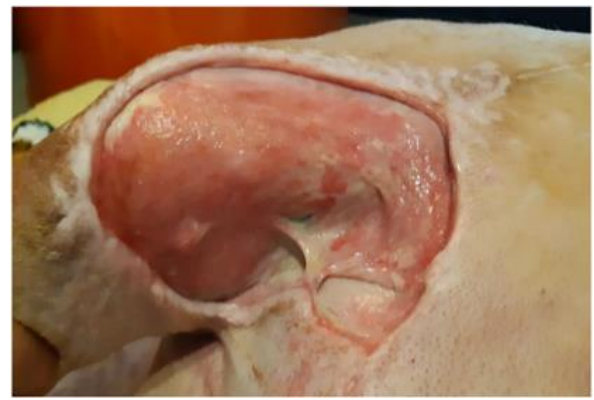

Figura 7. Processo de cicatrização avançado no últimos dias.

\section{Discussão}

$\mathrm{O}$ relato de caso apresenta um cão da raça American Bully que aos 13 anos de idade, pesando aproximadamente 40 quilos, foi diagnosticado com mastocitoma de alto grau através de exame citológico. $\mathrm{O}$ animal sendo idoso apresenta ser um desafio para o tratamento, ainda mais por conta da grande incidência de tumores de células redondas em seu organismo. Estudos apontam que este tipo de neoplasia acomete mais os cães quando comparada a outras espécies de animais domésticos (Romansik et al., 2007). São várias as raças atingidas por mastocitoma, American Bully é uma delas, assim como outras mais semelhantes Pitbull, Bull Terrier, e que também podem ser comprovadas em diversos artigos 
(Costa-Casagrande et al., 2008; De Nardi et al., 2002; Dobson \& Scase, 2007; Patnaik et al., 1984; Poggiani et al., 2012; Strefezzi et al., 2010; Welle et al., 2008). Há casos ainda em que até o porte do animal pode influenciar na incidência de tumores, como apresenta este estudo (White et al. 2011), quanto maior o porte maior a chance de desenvolver a doença. A idade é outro fator relevante como foi verificado em diversos artigos (Costa-Casagrande et al., 2008; De Nardi et al., 2002; Dobson \& Scase, 2007; Patnaik et al., 1984; Poggiani et al., 2012; Strefezzi et al., 2010; Welle et al., 2008) em que a faixa etária classificada é de oito a nove anos. Outras pesquisas, como a descrita por Costa-Casagrande et al. (2008) observaram incidência ainda maior em cães entre nove e 11 anos de idade. Este relato vai de encontro a todos, muito embora aponte idade superior aos estudos acima citados.

Este tipo de tumor pode acometer qualquer região do corpo, em especial os membros, região inguinal e prepucial (Natividade et al., 2014). Literaturas apontam que o grau de agressividade pode ser atribuído aos mastocitomas localizados em regiões inguinais, principalmente em machos (Dobson \& Scase, 2007) como presentado no presente relato. Blackwood et al. (2012) ressaltam em seu estudo, que como a localização é considerada de difícil acesso cirúrgico, e automaticamente, de difícil ressecção cirúrgica completa, isso torna o paciente mais propenso a uma recidiva local, como ocorreu neste relato de caso. Já Poggiani et al. (2012) não observaram correlação entre prognóstico e localização tumoral em seus estudos de casos.

A questão mais importante a ser discutida diz respeito à citologia aspirativa. Pode-se afirmar que diversas pesquisas que é uma metodologia bastante utilizada para o diagnóstico de tumores e o exame é realizado facilmente pois não há necessidade de sedação no paciente (Lavalle et al., 2003; Trindade et al., 2008). Contudo, as informações convergem quanto a agressão que o procedimento pode ou não causar ao paciente. Neste relato de caso constatou-se aumento significativo do tumor dias após o exame. A lesão que anteriormente media apenas três $\mathrm{cm}$, era bem delimitada e não apresentava processo inflamatório, obteve a piora significativa do quadro, chegou a medir mais de sete $\mathrm{cm}$ ao ponto da pele ulcerar, tornando a cirurgia impossível de ser realizada com margem de segurança.

De acordo com diversos autores como Stanclift \& Gilson (2008) a quimioterapia neoadjuvante tem a intenção de tornar cirúrgico uma lesão de difícil acesso, reduzindo o tamanho da lesão facilitando a ressecção com margens adequadas de segurança. Essa técnica foi empregada neste paciente uma vez que, no momento da consulta oncológica o cirurgião identificou um tumor inflamado, edemaciado e sem limites para remoção com margem.

A terapia instituída foi Vimblatina e Prednisolona que de acordo com o Dobson \& Scase (2007) e Webster et al. (2008) utilizam esse protocolo de primeira linha para mastocitoma. Após as duas primeiras sessões, o paciente não apresentou nenhuma melhora, sendo assim o tratamento interrompido e o animal foi encaminhado para a cirurgia. O procedimento cirúrgico, geralmente, é o tratamento de eleição para os mastocitomas, sendo que a quimioterapia, para os de grau III, deve ser sempre utilizada pelo fato de ter um alto potencial metastático (Cunha et al., 2017).

Uma das funções da eletroquimioterapia é ampliar as margens cirúrgicas em regiões tumorais que não estão bem delimitadas como aponta Spugnini \& Baldi (2014) e outros, indicando assim a administração em caso de excisão cirúrgica incompleta do mastocitoma, grau II ou grau III. Spugnini \& Baldi (2014) em seus estudos elegeu tanto a eletroquimioterapia quanto a bleomicina como tratamento, respeitando os intervalos de sessões. Em seus estudos os dados nos mostram vários casos de mastocitoma de alto grau com efeitos colaterais de degeneração de degranulação das células mastocitárias remanescentes após a cirurgia e três casos redicivantes, reforçando assim, a potencialidade e a eficácia da EQT em tratamentos com tumores de células redonda. Já no presente relato a recidiva do tumor em metástases ocorreu mesmo com a aplicação da EQT, constatando que apesar de haver segurança há também exceções.

Já que o paciente em questão não havia respondido ao tratamento de neoadjuvância optou-se pela eletroquimioterapia. $\mathrm{O}$ procedimento foi realizado com o animal no centro cirúrgico, imediatamente após a retirada do tumor, com o paciente ainda sedado. Mesmo com a inclusão de mais esse procedimento, constatou-se que não foi efetiva o suficiente para a destruição do mastocitoma residual e além disso, corroborou com o processo de deiscência da cirurgia.

A deiscência é a maior das complicações em casos de cirurgias reconstrutivas que se pode encontrar e a mais citada por diversos autores, alguns deles, como o Furlani et al. (2008) citam em seu estudo com 
resseção de mastocitoma e alguns autores que realizaram pesquisas com cirurgias reconstrutivas que mesmo com planejamento e uso de protocolos e técnicas adequadas há possibilidade de ocorrer excesso de tensão no fechamento da ferida e contaminação. Elas ocorrerem por vários motivos entre eles: cirurgias em região de dobra, acomete pacientes com sobrepeso, animais idosos, com artrose, ou que tem predisposição a ficar mais tempo deitado, que esteja debilitado pelo tratamento de quimioterapia, ou seja, todas as complicações citadas nas mais diversas técnicas cirúrgicas reconstrutivas.

No presente trabalho os autores compreendem que as complicações observadas foram decorrentes ao exame citológico que, mesmo identificando o tipo de tumor, também acelerou o processo de tal forma que todos os outros tratamentos indicados não surtiram resultado, isso se emprega aos quimioterápicos, às cirurgias reconstrutivas e inclusive a eletroquimioterapia.

\section{Conclusão}

No presente relato, nem a neoadjuvância, a eletroquimioterapia, e nem as duas ressecções cirúrgicas foram suficientes para impedir a recidiva e trazer a qualidade de vida para o animal.

\section{Referências}

Blackwood, L., Murphy, S., Buracco, P., De Vos, J. P., De Fornel-Thibaud, P., Hirschberger, J., Kessler, M., Pastor, J., Ponce, F., \& Savary-Bataille, K. (2012). European consensus document on mast cell tumours in dogs and cats. Veterinary and Comparative Oncology, 10(3), e1-e29. DOI: https://doi.org/10.1111/j.1476-5829.2012.00341.x

Cemazar, M., Tamzali, Y., Sersa, G., Tozon, N., Mir, L. M., Miklavcic, D., Lowe, R., \& Teissie, J. (2008). Electrochemotherapy in veterinary oncology. Journal of Veterinary Internal Medicine, 22(4), 826-831. DOI: https://doi.org/10.1007/978-3-319-32886-7_107

Costa-Casagrande, T. A., Elias, D. S., Melo, S. R., \& Matera, J. M. (2008). Estudo retrospectivo do mastocitoma canino no serviço de cirurgia de pequenos animais-Hospital Veterinário da Faculdade de Medicina Veterinária e Zootecnia da Universidade de São Paulo. Archives of Veterinary Science, 13(3), 176-183. DOI: https://doi.org/10.5380/avs.v13i3.11667

Cunha, S. C. S., Corgozinho, K. B., Valga, S., \& Ferreira, A. M. R. (2017). Tratamento de um mastocitoma de alto grau na língua de um cão por meio de radioterapia e quimioterapia: relato de caso. Arquivo Brasileiro de Medicina Veterinária e Zootecnia, 69(1), 101-105. DOI: https://doi.org/10.1590/1678-4162-8331

Daleck, C. R., Fonseca, C. S., \& Canola, J. C. (2016). Oncologia em cães e gatos. Roca.

De Nardi, A. B., Rodaski, S., Sousa, R. S., Costa, T. A., Macedo, T. R., Rodigheri, S. M., Rios, A., \& Piekarz, C. H. (2002). Prevalência de neoplasias e modalidades de tratamentos em cães, atendidos no hospital veterinário da Universidade Federal do Paraná. Archives of Veterinary Science, 7(2), 15 26. DOI: https://doi.org/10.5380/avs.v7i2.3977

Dean, P. W. (1988). Mast cell tumors in dog: diagnosis, treatment and prognosis. Veterinary Medicine, 83, 185-192.

Dobson, J. M., \& Scase, T. J. (2007). Advances in the diagnosis and management of cutaneous mast cell tumours in dogs. Journal of Small Animal Practice, 48(8), 424-431. DOI: https://doi.org/10.1111/j.1748-5827.2007.00366.x

Furlani, J. M., Daleck, C. R., Vicenti, F. A. M., De Nardi, A. B., Pereira, G. T., Santana, Á. E., Eurides, D., \& da Silva, L. A. F. (2008). Mastocitoma canino: estudo retrospectivo. Ciência Animal Brasileira, 9(1), 242-250.

Instituto Nacional do Câncer (INCA/MS): Estadiamento. Disponível em: https://www.inca.gov.br/estadiamento. Acesso em 23 de maio de 2020.

Jarrett, W. F. H., \& Mackey, L. J. (1974). Neoplastic diseases of the haematopoietic and lymphoid tissues. Bulletin of the World Health Organization, 50(1-2), 21-34.

Lavalle, G. E., Araújo, R. B., Carneiro, R. A., \& Pereira, L. C. (2003). Punção aspirativa por agulha fina para diagnóstico de mastocitoma em cães. Arquivo Brasileiro de Medicina Veterinária e Zootecnia, 55(4), 500-502. DOI: https://doi.org/10.1590/s0102-09352003000400017 
Miller, W. H., Griffin, C. E., Campbell, K. L., \& Muller, G. H. (2013). Muller and Kirk's Small Animal Dermatology. Elsevier Health Sciences.

Mir, L. M., Orlowski, S., Belehradek Junior, J., \& Paoletti, C. (1991). Electrochemotherapy potentiation of antitumour effect of bleomycin by local electric pulses. European Journal of Cancer and Clinical Oncology, 27(1), 68-72. DOI: https://doi.org/10.1016/0277-5379(91)90064-K

Misdorp, W. (2004). Mast cells and canine mast cell tumours. A review. Veterinary Quarterly, 26(4), 156-169. DOI: https://doi.org/10.1080/01652176.2004.9695178

Morris, J., \& Dobson, J. M. (2001). Small animal oncology. Wiley Online Library.

Natividade, F. S., Castro, M. B., Silva, A. S., Oliveira, L. B., McManus, C. M., \& Galera, P. D. (2014). Análise de sobrevida e fatores prognósticos de cães com mastocitoma cutâneo. Pesquisa Veterinária Brasileira, 34(9), 874-884. DOI: https://doi.org/10.1590/s0100-736x2014000900012

Navega, P. R. da S. (2011). Mastocitomas em canídeos: estudo retrospectivo. Universidade Técnica de Lisboa. Faculdade de Medicina Veterinária.

Okino, M., \& Mohri, H. (1987). Effects of a high-voltage electrical impulse and an anticancer drug on in vivo growing tumors. Japanese Journal of Cancer Research, 78(12), 1319-1321. DOI: https://doi.org/10.1007/BF02470769

Patnaik, A. K., Ehler, W. J., \& MacEwen, E. G. (1984). Canine cutaneous mast cell tumor: morphologic grading and survival time in 83 dogs. Veterinary Pathology, 21(5), 469-474. DOI: https://doi.org/10.1177/030098588402100503

Poggiani, S. S. C., Terra, E. M., Torres Neto, R. T., Costa, M. T., \& Amorim, R. L. (2012). Canine cutaneous mast cell tumor: biologic behavior and its correlation with prognostic indicators. Open Journal of Veterinary Medicine, 2(4), 255-261. DOI: https://doi.org/10.4236/ojvm.2012.24041

Rangel, M. M. M., Fernandes, N. C. C., Nagamine, M. K., Fukumasu, H., Oliveira, K. D., Lowe, R., Mir, L. M., Sinhorini, I. L., \& Dagli, M. L. Z. (2008). Eletroquimioterapia: uma nova promessa para o tratamento de cânceres em animais. Clínica Veterinária, 13(75), 30-36.

Romansik, E. M., Reilly, C. M., Kass, P. H., Moore, P. F., \& London, C. A. (2007). Mitotic index is predictive for survival for canine cutaneous mast cell tumors. Veterinary Pathology, 44(3), 335-341. DOI: https://doi.org/10.1354/vp.44-3-335

Sledge, D. G., Webster, J., \& Kiupel, M. (2016). Canine cutaneous mast cell tumors: A combined clinical and pathologic approach to diagnosis, prognosis, and treatment selection. The Veterinary Journal, 215, 43-54. DOI: https://doi.org/10.1016/j.tvjl.2016.06.003

Souza, A. C. F., Pascoli, A. L., Ferreira, M. G. P. A., Reis Filho, N. P., Silva, I. C. R., Santos, R. R., Faro, A. M., \& Nardi, A. B. (2018). Mastocitoma cutâneo canino: estudo retrospectivo dos casos atendidos pelo Serviço de Oncologia do Hospital Veterinário da FCAV-Unesp, Campus Jaboticabal, de 2005 a 2015. Pesquisa Veterinária Brasileira, 38(9), 1808-1817. DOI: https://doi.org/10.1590/1678-5150-pvb-5150

Spugnini, E. P., \& Baldi, A. (2014). Electrochemotherapy in veterinary oncology: from rescue to first line therapy. Methods Molecular Biology, 1121, 247-256.

Stanclift, R. M., \& Gilson, S. D. (2008). Evaluation of neoadjuvant prednisone administration and surgical excision in treatment of cutaneous mast cell tumors in dogs. Journal of the American Veterinary Medical Association, 232(1), 53-62. DOI: https://doi.org/10.2460/javma.232.1.53

Strefezzi, R. F., Kleeb, S. R., Xavier, J. G., \& Dias, J. L. C. (2010). Avaliação da proliferação celular como indicador prognóstico para mastocitomas cutâneos caninos. Pesquisa Veterinária Brasileira, 30(7), 559-565.

Trindade, D. B. M., Cavalheiro, A. L. B., Lopes, A. A., Santurio, S. T., Mazzanti, J. M., \& Eduardo Schossler, J. E. (2008). Diagnóstico de criptococose canina pela citologia aspirativa por agulha fina. Ciência Rural, 38(3), 1-6.

Vascellari, M., Giantin, M., Capello, K., Carminato, A., Morello, E. M., Vercelli, A., Granato, A., Buracco, P., Dacasto, M., \& Mutinelli, F. (2013). Expression of Ki67, BCL-2, and COX-2 in canine cutaneous mast cell tumors: association with grading and prognosis. Veterinary Pathology, 50(1), 110-121. DOI: https://doi.org/10.1177/0300985812447829 
Webster, J. D., Yuzbasiyan-Gurkan, V., Thamm, D. H., Hamilton, E., \& Kiupel, M. (2008). Evaluation of prognostic markers for canine mast cell tumors treated with vinblastine and prednisone. $B M C$ Veterinary Research, 4(1), 1-8. DOI: https://doi.org/10.1186/1746-6148-4-32

Welle, M. M., Bley, C. R., Howard, J., \& Rüfenacht, S. (2008). Canine mast cell tumours: a review of the pathogenesis, clinical features, pathology and treatment. Veterinary Dermatology, 19(6), 321-339.

White, C.R., Hohenhaus, A.E., Kelsey, J., Procter-Gray, E. (2011). Cutaneous MCTs: Associations with Spay/Neuter Status, Breed, Body Size, and Phylogenetic Cluster. Journal of the American Animal Hospital Association, 47 (3): 210-216. https://doi.org/10.5326/jaaha-ms-5621

Withrow, S. J., Page, R., \& Vail, D. M. (2013). Small Animal Clinical Oncology-E-Book. Elsevier Health Sciences.

\section{Histórico do artigo:}

Recebido: 19 de setembro de 2020 .

Aprovado: 18 de outubro de 2020.

Disponível online: 19 de janeiro de 2021
Licenciamento: Este artigo é publicado na modalidade Acesso Aberto sob a licença Creative Commons Atribuição 4.0 (CC-BY 4.0), a qual permite uso irrestrito, distribuição, reprodução em qualquer meio, desde que o autor e a fonte sejam devidamente creditados. 